\title{
Author Correction: A harmonized atlas of mouse spinal cord cell types and their spatial organization
}

\author{
Daniel E. Russ (D), Ryan B. Patterson Cross, Li Li, Stephanie C. Koch (1), Kaya J. E. Matson, Archana Yadav, \\ Mor R. Alkaslasi (1D, Dylan I. Lee (B), Claire E. Le Pichon (D), Vilas Menon (1) \& Ariel J. Levine (1)
}

Correction to: Nature Communications https://doi.org/10.1038/s41467-021-25125-1, published online 29 September 2021.

The original HTML version of this Article did not link to Supplementary Tables 1 to 8 . This has been corrected in the HTML version of the article.

The original version of this Article contained an error in the Results subsection entitled 'Developmental lineages of postnatal spinal neuron populations', in which a sentence incorrectly referred to Supplementary Table 6 instead of Supplementary Table 5. The incorrect sentence reads 'In addition, the identity of the individual embryonic cells that were closest in PC-space to each cluster were also determined (Supplementary Table 6)'. The correct version states '(Supplementary Table 5)' in place of '(Supplementary Table 6)'.

The original version of this Article contained an error in Methods subsection entitled 'Published data acquisition', in which one sentence omitted to cite Supplementary Table 7. The incorrect sentence read 'Published data were downloaded from the NCBI Sequence Read Archive (SRA)'. The correct version adds 'and are available in Supplementary Table 7' after '(SRA)'.

The original version of this Article contained an error in the Methods subsection entitled 'Clustering', in which a sentence incorrectly referred to Supplementary Table 5 instead of Supplementary Table 7. The incorrect sentence read 'The meta-data (and associated final cell labels) are available in Supplementary Table 5'. The correct version states 'Supplementary Table 7' in place of 'Supplementary Table 5'.

The original version of this Article contained errors in the Methods subsection entitled 'Supplementary Analysis Notes'. A sentence incorrectly referred to Supplementary Table 6 instead of Supplementary Table 2. The incorrect sentence read 'In examining cluster composition, we found that only studies that used nuclei contributed to MN-alpha, MN-gamma, or PGC cells as well as Excit-7 and most ventral neuronal clusters (Supplementary Table 6).' The correct version states '(Supplementary Table 2)' in place of '(Supplementary Table 6)'. In addition, two sentences incorrectly referred to Supplementary Table 6 instead of Supplementary Table 8. The incorrect sentences read 'GO analysis revealed that all of the enriched gene annotation clusters were associated with basic cell metabolism terms such as the ribosome, metabolic pathways, and proton transport (Supplementary Table 6).' and 'To further probe genes that were enriched in nuclei compared to cells, we sorted all significant genes in each cluster by the average log fold change, selected genes with a value $>2$ (nuclei $>$ cells), and identified a list of 10 protein-coding genes and 3 lncRNAs (Supplementary Table 6)'. The correct versions state '(Supplementary Table 8)' in place of '(Supplementary Table 6)'.

These errors have been corrected in the PDF and HTML versions of the Article.

Published online: 18 February 2022

\section{Additional information}

Supplementary information The online version contains supplementary material available at https://doi.org/10.1038/s41467-022-28698-7. 
(c) Open Access This article is licensed under a Creative Commons Attribution 4.0 International License, which permits use, sharing, adaptation, distribution and reproduction in any medium or format, as long as you give appropriate credit to the original author(s) and the source, provide a link to the Creative Commons license, and indicate if changes were made. The images or other third party material in this article are included in the article's Creative Commons license, unless indicated otherwise in a credit line to the material. If material is not included in the article's Creative Commons license and your intended use is not permitted by statutory regulation or exceeds the permitted use, you will need to obtain permission directly from the copyright holder. To view a copy of this license, visit http://creativecommons.org/licenses/by/4.0/.

This is a U.S. Government work and not under copyright protection in the US; foreign copyright protection may apply 2022 